\title{
LITERATURA DIGITAL INTERATIVA, UMA LITERATURA À MEDIDA DO NOSSO TEMPO
}

\author{
Isa Mestre \\ Universidade do Algarve/CIAC \\ aimestre@ualg.pt
}

\section{Resumo}

A partir da análise da narrativa digital interativa Pry procuramos compreender a existência de uma relação dialogante entre literatura digital interativa e contemporaneidade. Promovemos, deste modo, um entendimento da literatura digital interativa como fruto do nosso tempo, como reflexo da vivência e das características da contemporaneidade. Neste sentido, servimo-nos da contemporaneidade como ferramenta privilegiada para compreender a natureza formal das obras velocidade, a efemeridade, a liquidez e a processualidade, características da era contemporânea, se encontram também presentes neste tipo de obras literárias.

Palavras-Chave: Literatura digital. Narrativa interativa. Contemporaneidade.

\section{INTERACTIVE DIGITAL LITERATURE, A LITERATURE TO MEASURE IN OUR TIME}

\begin{abstract}
From the analysis of interactive digital narrative Pry we try to understand the existence of a dialogical relationship between interactive digital literature and contemporaneity. In this way, we promote an understanding of interactive digital literature as a result of our time, as a reflection of the experience and characteristics of the contemporary world. In this sense, we use contemporaneity as a privileged tool to understand the formal nature of works speed, ephemerality, liquidity and processuality, characteristics of the contemporary era, are also present in this type of literary works.
\end{abstract}

Keywords: Digital literature. Interactive narrative. Contemporaneity.

\section{Introdução}

Centrando-nos no universo das narrativas digitais interativas para iPad, e tomando, a título de exemplo, a obra digital interativa Pry, produzida, em 2014, pela Tender Claws, procuraremos, ao longo deste artigo, comprovar a existência de uma relação dialogante entre literatura digital

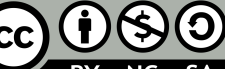


interativa e contemporaneidade.

Assim, debruçando-nos sobre esta obra e, especificamente, sobre as suas características formais, promoveremos um entendimento da literatura digital interativa como fruto do nosso tempo, como reflexo da vivência e das características da contemporaneidade.

Deste modo, servir-nos-emos, ao longo deste artigo, da contemporaneidade, por via da teorização de diversos sociólogos e teóricos, como ferramenta privilegiada para compreender a natureza formal das obras literárias digitais, mostrando, assim, que questões como a fragmentaridade, a multiplicidade, a velocidade, a efemeridade, a liquidez $\mathrm{e}$ a processualidade, características da era contemporânea, estão também marcadamente presentes na forma de ser deste tipo de obras.

Deste modo, e começando por afirmar a literatura digital interativa como movimento de continuidade e rutura pretendemos, em seguida, compreender o relacionamento da literatura digital e das suas formas à luz do tempo e das características da época na qual é produzida.

Assim, sugerimos, portanto, numa primeira abordagem, que olhar a literatura digital implica olhar as características da contemporaneidade e ver, à luz delas, uma literatura que, sendo a mesma de sempre (uma vez que é alimentada por um movimento de continuidade marcado pela evolução das formas e dos suportes) é, simultaneamente, a literatura de hoje - reflexo das características da nossa era e do nosso tempo.

Desta forma, procuraremos, ao longo deste artigo, afirmar a ideia de que a literatura digital é moldada, na sua essência, pela contemporaneidade tornando-se, nesta perspectiva, as narrativas digitais interativas - constituídas formalmente a partir das características da época na qual surgem - promontórios a partir dos quais consideramos ser possível lançar um olhar sobre as formas literárias anteriores que com elas entram em diálogo, antecipando, avant la lettre, muitas das suas características.

Sublinhe-se, a justificar a nossa proposta, que, de fato, as formas de expressão da contemporaneidade parecem estar perfeitamente adaptadas para capturar a velocidade, a volatilidade e a multiplicidade características da era digital.

Em suma, diante do exposto, acreditamos, portanto, que a contemporaneidade parece ter-nos treinado para as condições sociais, culturais e artísticas da segunda metade do século XX e do início do século XXI, especialmente para o aparecimento das novas tecnologias, tendo antecipado, do ponto de vista estético e estrutural, algumas das características que hoje encontramos nas formas literárias digitais.

Ora, assim sendo, e propondo, portanto, esta relação dialogante, apontaremos, em seguida, para um conjunto de características da era contemporânea que parecem ser consensuais com 
as características das obras literárias digitais e, nomeadamente, da narrativa digital interativa. Pretendemos, deste modo, sugerir que a literatura digital incorpora e absorve as particularidades e o modo de vida da contemporaneidade para os usar ao serviço da criação de novas formas poéticas.

Desta forma, centrar-nos-emos na hipótese de que a contemporaneidade, a partir da terceira revolução industrial - apontada por muitos como revolução do conhecimento (CASTELLS, 1999) (HARGREAVES, 2003) - marcada pela introdução da informática, da nanotecnologia e da biotecnologia - possa estar a proporcionar-nos uma plataforma privilegiada para observarmos o fenómeno da literatura digital.

Nesta perspectiva, será partindo do pressuposto de que, de acordo com os estudos e as perspectivas de diversos autores, a contemporaneidade impõe: novas concepções sobre o espaço e sobre o tempo; novas relações fluídas, efêmeras e voláteis e a fragmentação do discurso e do indivíduo, que defendemos que se equacione a hipótese da literatura digital absorver e reproduzir algumas destas características manifestando-as, diretamente, no momento de criação e concepção das obras literárias digitais.

\section{Novas concepções sobre o espaço e sobre o tempo}

Assim, e partindo do primeiro pressuposto - o de que a contemporaneidade impõe novas concepções sobre o espaço e sobre o tempo - começaremos por observar que, de fato, a transição de uma era industrial a uma era pós-industrial implica mudanças às quais o individuo não é alheio.

Se admitirmos que toda a interação social se situa num determinado tempo e num determinado espaço é-nos possível observar que, de fato, grande parte das nossas rotinas diárias são delimitadas pela combinação destas duas variáveis. No entanto, se pensarmos, como sugerem Frezza, Grisci \& Kessler (2009, p. 489) que “(...) em cada momento, modo de produção e de organização humana, se dá a construção de uma maneira específica de se perceber, conceitualizar e experimentar o espaço e o tempo" então, de fato, estamos em condições de assumir que a introdução dos meios digitais nos permite um olhar sobre novos modos de conceber o espaço e o tempo na realidade digital.

Se, como explica Nicholas Negroponte (1995), a era industrial, tendo introduzido o conceito de "produção em massa", parece ter promovido uma economia regida por métodos uniformes e estandardizados, fixos num determinado tempo e num determinado espaço, a era da informação, por sua vez, parece apresentar uma menor dependência do espaço e do tempo.

De acordo com David Harvey (2004) a contemporaneidade promove, assim, um efeito de 
compressão do espaço e do tempo que resulta do desenvolvimento das indústrias de transportes, da comunicação e, sobretudo, da informática. Segundo o autor, esta compressão do espaço e do tempo estaria, então, relacionada com um conjunto de processos que revolucionam as qualidades objetivas destas duas entidades e que nos obrigam, consequentemente, a alterar o modo como representamos o mundo. Na verdade, res como a aceleração capitalista do ritmo de vida ou a superação de barreiras espaciais por via das potencialidades dos novos dispositivos eletrônicos impõem-nos a necessidade de um novo olhar sobre este assunto.

Ora, tendo em conta esta realidade, defenderemos, como sublinha Ramon Tessmann (2013), que através dos meios digitais e, mais especificamente, dos meios de comunicação online, "espaço e tempo anulam-se" uma vez que "hoje, o tempo não é mais linear, mas sim, fragmentado" (TESSMAN, 2013), não existindo um início e um fim da linha do tempo, e o espaço já não apresenta fronteiras geográficas, sendo tudo acessível por meio da rede.

Assim, focando-nos primeiramente na anulação do espaço promovida pela tecnologia digital, consideramos importante começar por sublinhar o fato de que, com o desenvolvimento das tecnologias da informação e da comunicação, a noção de espaço enquanto entidade fixa e estável desaparece. Como sugere Bauman (1999), “as distâncias já não importam, ao passo que uma ideia de fronteira geográfica é cada vez mais difícil de sustentar". Na verdade, com a emergência do ciberespaço, local a partir do qual é possível o acesso instantâneo, à distância de apenas um clique, a qualquer parte do mundo e a qualquer informação, fragilizam-se as noções de espaço físico.

Nesta perspectiva, admitindo que a rede permite que qualquer um, em qualquer lugar, tenha acesso a um conjunto de informações provenientes dos mais diversos e longínquos pontos, faz sentido considerarmos, como sugere Ladislau Dowbor (2009), que, com a emergência do digital, assistimos a um processo de desterritorialização. Se, como refere o autor, "tecnologia é desterritorialização" (DOWBOR, 2009, p. 56) então é importante sublinhar que a emergência da sociedade em rede provoca, a partir do século XX e início do século XXI, novas formas de interação que facilitam o trânsito entre pessoas e territórios distantes e que, simultaneamente, nos oferecem uma nova concepção do espaço. Se, como sublinha Negroponte, na era digital:

Los bits se podían fabricar en cualquier lugar, en cualquier momento y se podían mover, por ejemplo, entre las bolsas de Nueva York, Londres y Tokio como si fueran tres herramientas de la misma máquina (...), (NEGROPONTE, 2000, p. 100). 
Então, diante desta mobilidade, notamos que, do mesmo modo que o hipertexto permite superar as limitações da página impressa, também a era digital parece superar, em primeira instância, a própria localização geográfica. Repare-se que, de fato, com o desenvolvimento das tecnologias da informação e da comunicação, e mais especificamente com o aparecimento da internet, a sociedade moderna passa a relacionar-se, em grande medida, por transações pessoais indiretas (mediadas por máquinas) sem necessidade de qualquer tipo de copresença. Neste contexto, todo o mundo está, hipoteticamente, à distância de um clique.

Por outro lado, e no que diz respeito à questão do tempo, podemos também observar, com o surgimento da era da informação, o espoletar de uma nova concepção no que diz respeito a esta categoria. Afetado pelo aceleramento do ritmo de vida o tempo é, na era digital, encurtado, sendo, ele próprio, marcado pela instantaneidade.

Observe-se, a este respeito, que, como sublinha Karr:

(...) a internet está a fazer-nos esperar por respostas e informação muito rápidas e a treinar-nos para que, a cada vez que clicamos num link, tenhamos informação no minuto seguinte. (...) Esta mudança da forma como percepcionamos o tempo e a nossa necessidade de resposta imediata influencia definitivamente a forma como usamos os media em geral. Esperamos muito mais estímulos e respostas muito mais rápidas do que as que tivemos no passado. (KARR, 2012).

Assim, no digital, o único tempo que parece existir é, de fato, o do aqui e do agora, o da instantaneidade, sendo que, como aponta Tessman, na era da internet, "a nova unidade de medida do tempo é o tempo real" (TESSMAN, 2013). Ideia semelhante defende Anderson (1999) para quem a grande chave para a compreensão da era contemporânea é a instantaneidade. De acordo com o teórico, o contemporâneo "é sempre (...) o que se deve chamar um presente absoluto" (ANDERSON, 1999, p. 20) na medida em que, como esclarece, no meio digital, parece haver uma dificuldade peculiar em definir um presente e um passado relativos.

Desta forma, e à luz desta concepção, destacamos, portanto, que uma das características mais marcantes da contemporaneidade é, efetivamente, a relação que o indivíduo, através dos novos meios, mantém com o tempo. Sublinhe-se, a este respeito, e a justificar a relação, que esta era introduz, pela primeira vez, a ideia de que o tempo se pode libertar do espaço, tornando-se uma unidade independente. Decorrente desta possibilidade de autonomização surge, então, como um dos traços definidores da contemporaneidade, a relativização do 
tempo. Recorde-se que sobre este tópico discorrem Maffesoli (1999) - que considera que a contemporaneidade promove um "presenteísmo"; Jameson (1991) - que utiliza o termo "presente perpétuo" e Bauman (2001) - que, destacando o carácter relativo e cada vez mais subjetivo do tempo na era contemporânea, usa o conceito de "modernidade líquida" para mostrar que a relação entre tempo e espaço deve ser vista como um processo líquido, mutável e dinâmico, e não, como algo estagnado ou pré-determinado.

Nessa mesma perspectiva, defende Bauman que o instantâneo, considerado enquanto elemento característico da contemporaneidade, se sobrepõe ao fixo e ao durável. Renasce, daí a máxima do carpe diem, a ideia de que o homem moderno, atravessado pela fugacidade do mundo e da vida, deve aprender um novo modo de se relacionar com o tempo.

Ora, neste sentido, observamos, portanto, que diante de uma nova concepção do tempo fugaz, instantâneo e fragmentado - o homem pós-moderno aprende a viver o "eterno presente", a quebrar a sensação de que a velocidade do mundo lhe impõe limites.

Em suma, como sugere Virilio (1999, p. 115), a contemporaneidade parece ensinar o sujeito a viver a "instantaneidade de um tempo mundial e universal", situando-se, assim, num "eterno presente", num tempo onde passado, presente e futuro se anulam em detrimento do momento instantâneo.

Ora, assim sendo, e uma vez apontados os principais argumentos que justificam a ideia de que a era contemporânea promove o aparecimento de uma nova concepção de espaço e de tempo, interessa-nos agora, particularmente, focar-nos no modo como a literatura digital, enquanto produto desta era, parece reproduzir, na sua essência, estas novas concepções.

Assim, partindo da questão do espaço, e focando-nos especificamente nos suportes e, mais concretamente, na sua fisicalidade, gostaríamos de começar por observar que a narrativa digital interativa parece promover, no nosso entender, uma desterritorialização do texto que, de uma existência física, palpável e factual, associada ao suporte impresso, passa a ter, no digital, uma existência meramente virtual.

Desta forma, se considerarmos que antes do aparecimento dos meios digitais as narrativas textuais eram, maioritariamente, fixadas em suportes materiais, é preciso observar, portanto, que, a partir do advento do computador e, mais recentemente, a partir do surgimento da internet, a narrativa começa a ter capacidade para se libertar dessa materialidade, e consequentemente, dessa espacialidade, assumindo uma forma virtual que a transforma em algo "leve", que, devido às potencialidades dos novos suportes, pode ser transportado, em segundos, para qualquer dispositivo digital, em qualquer ponto do globo.

Neste sentido, a narrativa deixa de existir, fisicamente, no espaço do livro para passar a 
existir, de modo desmaterializado, no espaço digital. Dito de outro modo: impossibilitado de ser encerrado na sua materialidade física, o livro digital interativo pode hoje, devido ao meio em que se encontra, expandir-se e alargar-se a uma rede mundial de conexões que fragiliza, do ponto de vista geográfico, a noção de localização física do texto.

Assim, e retomando a ideia anteriormente avançada, se podemos afirmar que as obras impressas se encontram fisicamente materializadas no papel, já no caso das obras digitais consideramos, pelo contrário, que estas vivem, em parte, "algures entre bits e bytes", num espaço indeterminado: o ciberespaço.

Assim, atente-se, neste sentido, que uma obra literária digital tem potencial para estar em toda a parte não, estando, na verdade, fisicamente e eternamente concretizada em parte alguma. Sublinhe-se, a este respeito, que, de fato, ao lermos um texto digital estamos, efetivamente, a ler um texto imaterializado, de carácter virtual, que existe imanentemente dentro da máquina que o reproduz (neste caso dentro do iPad) não existindo, no entanto, no espaço físico a partir do qual o percecionamos.

Neste sentido, sugerimos, portanto, que o texto digital, desmaterializado, cria, através do suporte, uma hiper-realidade, construída e artificial, à qual o leitor tem acesso, proporcionando-lhe, no entanto, através da máquina, a sensação de aceder à própria realidade. Ora, nesta linha de pensamento, e partindo do conceito de "desterritorialização", proposto por Ladislau Dowbor (2009), sugerimos, portanto, que se considere a possibilidade da literatura digital, através da narrativa interativa, devido às propriedades do suporte que a alberga e às particularidades do meio que a acolhe, promover, também ela, uma "desterritorialização" do texto e, (de modo mais amplo), do livro, do espaço fixo e estável do impresso, para a imaterialidade, intangibilidade e virtualidade do espaço digital.

Assim, e reforçando a noção de que a literatura digital é uma literatura desterritorializada, sublinhamos, portanto, que o texto digital existe, espacial e imaterialmente, num ambiente virtual a partir do qual o leitor acede a ele.

Note-se, a este respeito, que, de fato, o novo ambiente em que as narrativas se começam a fixar - o ciberespaço - é, em si mesmo, um "não lugar-digital”, móvel, flutuante, efémero e desmaterializado. Como sublinha Santaella trata-se, afinal, de um meio "só indiretamente tangível, feito de presenças sempre mutáveis, líquidas” (SANTAELLA, 2007, p.17).

No que diz respeito ao tempo, é também possível observar, a partir da narrativa digital interativa, uma mudança de estado relativamente a esta categoria. Sublinhando, uma vez mais, a ideia de aceleramento do ritmo de vida, e adicionalmente, com a introdução das tecnologias da informação e da comunicação, a ideia de aceleramento proporcionado pela velocidade das 
máquinas eletrônicas, interessa-nos particularmente explorar o modo como a narrativa digital, reproduzindo os ideais contemporâneos, manifesta, através das suas produções, a instantaneidade, a fugacidade e a velocidade características desta era.

Assinale-se a este respeito que uma das características do texto digital diz precisamente respeito ao seu dinamismo e efemeridade. Repare-se, assim, que à semelhança do contexto em que é produzido, um mundo onde as realidades estão em constante transformação e onde o tempo corre veloz, também o tex to digital parece reproduzir esse ideal de rápida mutabilidade, afirmando-se, não como um ente estático, que, com limites formais bem definidos, é sempre percecionado da mesma forma, mas, pelo contrário, como um ente dinâmico que vai adquirindo, ao longo da sua vida, formas efémeras em constante mutação.

A este respeito note-se que, se como defendem autores como Landow (1995), Reis (2006) e Babo (2004), as obras impressas surgem, normalmente, como obras de carácter menos dinâmico que se apresentam ao leitor quase sempre da mesma forma (exceptuando alterações de umas edições a outras), as obras digitais, por seu turno, encontram-se, pela sua modularidade e fragmentariedade, em constante atualização. Deste modo, observamos, portanto, que o digital parece proporcionar o aparecimento de um texto temporalmente efémero, em constante construção e renegociação, que desafia a concepção tradicional de tempo associada às obras impressas uma vez que, diferentemente destas, apresenta, a partir das suas particularidades, a possibilidade de poder ser alterado cada vez que um dos seus componentes é modificado ou trabalhado.

Assim sendo, sugerimos, portanto, que as obras literárias digitais se apresentam, em primeira instância, como obras instáveis e efémeras cuja durabilidade depende, acima de tudo, da estabilidade (ou falta dela) dos elementos que as constituem.

Por outro lado, e retomando os ideais de velocidade e instantaneidade, podemos observar, a partir da análise de Pry, que o texto digital, tratando-se de um texto com uma temporalidade muito específica, marcada pela existência de tempos de reprodução, de leitura e de interação ${ }^{1}$, sugere, ele próprio, através da sua materialidade, um potenciamento da concepção de temporalidade. Sendo marcado pela existência de um tempo de reprodução, de um tempo de

\footnotetext{
${ }^{1}$ Observamos, através da análise da obra digital interativa Pry, que este tipo de obras literárias digitais impõem a necessidade de, a partir da sua materialidade, pensar um alargamento da noção de tempo uma vez que deixamos de pensar apenas no tempo de leitura para passar a pensar, simultaneamente, no tempo de reprodução, fruição e execução do próprio texto em função da materialidade da máquina que o alberga. Trata-se, assim, de uma metamorfose que implica que se tome em linha de conta que a temporalidade de um texto digital parece ser, entre outros res, condicionada pelo próprio suporte. Assim, se ao lermos um texto impresso estamos sujeitos a uma temporalidade por nós determinada no momento da leitura, ao ler um texto digital, porém - e por tratar-se de um texto virtual que só após processos informáticos se atualiza no ecrã - vivemos uma diferente noção de temporalidade na medida em que toda a nossa experiência de leitura é afetada pelo modo como o suporte processa o texto - reproduzindo-o e regurgitando-o - num determinado tempo que é marcado pelo funcionamento material do dispositivo que o alberga.
} 
leitura e de um tempo de interação o texto digital impõe-nos a necessidade de pensarmos um elemento que, ao invés de se materializar apenas de modo estável e perpétuo no ecrã, surge, simultaneamente, como uma aparição veloz e fugidia que é condicionada pela materialidade do próprio suporte que lhe dá vida.

Assim, perdendo a força da estabilidade que o suporte fixo parecia emprestar-lhe, o texto digital ganha a possibilidade de, num novo ambiente, emergir e desaparecer à velocidade que quem programa a máquina assim o desejar.

Atente-se, a este respeito, como grande parte das páginas de Pry são, de fato, compostas por trechos de texto que, segundos após se materializarem no ecrã, desaparecem em seguida, sem deixar rastro e sem possibilidade de ser retomados ou repetidos. Ora estes trechos são, só por si, a prova de que é possível observar, na constituição do texto digital, uma opção pela velocidade, pelo dinamismo e pela efemeridade.

Ora, o que aqui pretendemos sugerir é que, de fato, esta forma de "ser" da literatura digital parece relacionar-se com a temporalidade acelerada, efémera, fugidia e veloz que marca toda a vivência do sujeito contemporâneo.

Admitimos, neste sentido, que sendo assolado pelo encurtamento do tempo, pela velocidade das máquinas e pela rapidez da vida, o sujeito contemporâneo tende a projetar, em certas práticas literárias do seu tempo (de entre as quais destacamos, com especial relevância, a literatura digital interativa), a velocidade, a instantaneidade e a fugacidade do mundo que o rodeia.

Por fim, e para fechar, no que diz respeito à questão da instantaneidade, vale a pena recordar que também ela é passível de ser verificada no texto digital. Sublinhe-se, a este respeito, que o carácter múltiplo da obra literária digital - com diversas possibilidades de realização transforma, consequentemente, cada uma das suas leituras numa leitura instantânea, efémera e volátil que, após realizada, parece "desfazer-se no ar"

Note-se ainda que, também do ponto de vista da interação, é possível verificar uma certa instantaneidade, uma vez que a máquina digital que reproduz o texto parece esperar do leitor um feedback instantâneo. Assim sendo, observamos, portanto, que tal como o indivíduo moderno, também o leitor parece ser, no digital, assolado pela fugacidade do texto que, uma vez manifestado, necessita de uma resposta interativa imediata e se assume apenas como uma realidade instantânea, provisória e pouco duradoura.

Deste modo, e tendo em conta a reflexão levada a cabo, interessa-nos aqui, particularmente,

\footnotetext{
${ }^{2}$ A aproximação é aqui estabelecida com vista ao paralelo com a ideia de Marshall Bergman (1982) de que, com o advento da modernidade, "tudo o que é sólido se desmancha no ar".
} 
sublinhar a ideia de que as evoluções técnicas da contemporaneidade, e muito especificamente, o aparecimento de meios e suportes digitais, sugerem um aceleramento do tempo e um encurtamento das distâncias que provocam, consequentemente, uma reconfiguração das noções de espaço e de tempo à luz da nova realidade digital.

Ora, assim sendo, e como demonstrámos, acreditamos ser possível observar, a partir da literatura digital, o modo como o sujeito da contemporaneidade, o indivíduo que hoje produz obras literárias digitais, parece absorver esta nova concepção pós-industrial e pós-moderna de espaço e de tempo, criando objetos literários que, na sua forma, a refletem e a mimetizam.

Deste modo, sugerimos, portanto, a ideia de que a literatura digital parece absorver e reproduzir, na sua forma de "ser" algumas das principais concepções da era contemporânea.

Assim, no nosso entender, conceitos como o de desterritorialização, instantaneidade e efemeridade são, eles próprios, enquanto marcas da contemporaneidade, parte integrante e definidora da identidade da literatura digital.

Ora, nesta perspectiva, interessa-nos mostrar que, de fato, a forma com que a literatura digital hoje se nos apresenta aparenta encontrar-se, entre outros aspetos, ancorada numa nova concepção espaciotemporal que marca a vivência do indivíduo moderno e pós-moderno.

\section{Relações fluídas, efêmeras, voláteis}

Na sua obra Modernidade Líquida (2001) Bauman convida-nos, a partir da metáfora dos líquidos, a observar a sociedade moderna como um espaço onde tudo parece ser essencialmente transitório, efémero e volátil.

Como sublinha o autor, a modernidade contribui, metaforicamente, para o derretimento das estruturas sólidas do capitalismo em detrimento do surgimento de estruturas mais leves, fluídas e móveis. Segundo ele, a passagem da fase "sólida" da modernidade para a fase "líquida" implica admitir que as organizações sociais já não podem manter a sua forma por muito tempo devendo, pelo contrário, decompor-se e dissolver-se constantemente de modo a recriar-se a cada momento.

Assim, na nossa era, mais do que nunca, a premissa de Berman (1982) de que "tudo o que é sólido se desmancha no ar" parece fazer cada vez mais sentido. Para Bauman (2001, pp. 1213), a modernidade apresenta-nos, então, uma era onde tudo é líquido, onde tudo é volátil, onde as relações humanas e a vida em conjunto (famílias, casais, grupos de amigos, afinidades) perdem consistência e estabilidade.

Sublinha o autor que a transição do sólido para o líquido, propiciada, entre outros res, pelo 
enfraquecimento da ideia de comunidade, pela queda das instituições norteadoras e pela responsabilização individual pelo sucesso e pelo fracasso da vida pessoal, parece recair, em traços gerais, sobre aspetos de insegurança e indeterminação que colocam em destaque a carência de certezas e a imprevisibilidade da vida moderna.

$\mathrm{Na}$ verdade, como refere o teórico, o modo de vida das pessoas parece ser, cada vez mais, pautado por valores efémeros: “As rotinas antigas e aparentemente eternas começaram a se desintegrar; os hábitos antigos e convenções começaram a mostrar sua idade e os rituais, sua debilidade" (BAUMAN, 2007, p. 100).

Ora esta quebra com o convencional, e sobretudo, a supervalorização do indivíduo em detrimento do Estado fazem com que possamos admitir que, na modernidade líquida proposta por Bauman, o homem transita de agente passivo - que apenas cumpre com normas rígidas que lhe são impostas pelas grandes instituições - a agente ativo - libertando-se das obrigações provenientes das "fontes de autoridade" e adotando um estilo de vida a partir do qual, aparentemente, apenas ele é responsável pelo seu sucesso ou pelo seu fracasso na vida pessoal.

Assim, podemos admitir que o modo de vida do homem contemporâneo, aparentemente mais liberto dos mecanismos de ordem social, passa a ser marcado pelo corte com o padrão, com a estabilidade, com a segurança, com a certeza. Agora tudo parece ser mais líquido, mais efémero. A sociedade contemporânea liberta-se das amarras do universal, do total e do certo para se entregar, definitivamente, a um tempo de indefinição e de insegurança.

O homem moderno está agora sozinho na construção da sua vida, do seu mundo e, consequentemente, da sua felicidade. Trata-se daquilo a que Bauman chama de "faça você mesmo" (2013), um imperativo que coloca nas mãos do cidadão a responsabilidade de criação e execução das suas próprias políticas, dos seus próprios caminhos. Na verdade, podemos observar que, de fato, desde pequenos exemplos até à responsabilidade pela vida em si, na sociedade contemporânea o indivíduo é convidado a assumir o controlo, a adotar uma posição ativa que lhe permita, a partir das suas escolhas individuais, gerar a sua própria felicidade e sucesso.

Por fim, e para terminar a nossa reflexão em torno da metáfora dos líquidos, resta-nos retomar aquele que, segundo Bauman, é mais um dos traços definidores da sociedade contemporânea: a incerteza e a instabilidade.

Se, como defende o autor, "a incerteza é o habitat natural da vida humana" (BAUMAN, 2009, p. 37) então, e no que diz respeito à identidade do individuo na sociedade contemporânea, a possibilidade de a construir, num mundo onde as coisas são instáveis, parece ser, 
aparentemente, uma tarefa quase impossível. Na verdade, se, como sugere Bauman, o indivíduo pode hoje "ir às compras no supermercado das identidades", criando e recriando a sua imagem a cada momento, então, de fato, como sublinha, "a identidade experimentada, vivida só pode ser mantida unida com o adesivo da fantasia" (BAUMAN, 2001, p. 98). Deste modo, sublinhamos, portanto, que o grau de liberdade de que o indivíduo dispõe hoje para, constantemente, criar e recriar a sua identidade contribui para que possamos olhar a contemporaneidade como espaço que impõe, ele próprio, a necessidade que o indivíduo permaneça em constante movimento.

Assim, a incerteza e a instabilidade da sociedade contemporânea parecem, então, assumir-se, elas próprias, como características de um Homem que deixou já de possuir uma identidade aglutinadora que o defina e que o sintetize, privilegiando, alternativamente, o desenvolvimento de uma identidade que flutua no ar, podendo ser construída e reconstruída a cada momento.

Desta perspectiva, e para fechar o tópico da incerteza e da instabilidade, consideramos estar em condições de poder observar que o mundo contemporâneo, ao invés de procurar uma forma estável de ser, ambiciona, acima de tudo, alimentar-se da liquidez e da possibilidade de, através de um processo de bricolage, construir e reconstruir formas, hipóteses e realidades.

Repare-se que, de fato, no que diz respeito à questão da efemeridade e da obsolescência, esta é especialmente passível de ser verificada através da tecnologia digital. Na verdade, com o advento das constantes produções tecnológicas digitais, que a cada passo oferecem mais inovação, parece ser possível admitir que sentimos, devido à velocidade de processamento dos meios digitais, de forma cada vez mais intensa, a impressão de uma maior efemeridade.

Nesta perspectiva, como sublinha Patrick Lichty (2003), a industrialização do final do século XX e o advento da era digital, permitindo-nos observar o aparecimento de uma série de novos meios (fotografia, cinema, internet) oferecem-nos, simultaneamente, a possibilidade de observar o fenômeno da sua efemeridade.

Para o autor, a efemeridade do digital parece, assim, estar relacionada com uma "ausência cada vez maior de materialismo na produção de artefatos culturais na era digital" (LICHTY, 2003, p. 206). Sublinhe-se, a este respeito, que, de fato, se observarmos que toda a evolução digital é processada no meio virtual, sem deixar qualquer rastro físico, podemos admitir que, efetivamente, à medida que os meios computadorizados e, sobretudo os seus suportes, envelhecem, os seus conteúdos tendem a enfraquecer rapidamente, passando da degradação à completa obsolescência.

Para Patrick Lichty (2003), a memória digital, por ter vida curta, parece, então, abrir-nos o 
pano sobre a natureza efémera das comunicações e das práticas comunicativas na contemporaneidade. Como sublinha o autor, a respeito do rápido avanço da tecnologia e da obsolescência no meio digital:

Nessas duas décadas de meu envolvimento com computação, no mínimo cinco formas de armazenamento de dados em disquete, seis sistemas completos de operação de computador e três alfabetos digitais tornaram-se obsoletos. (LICHTY, 2003, p. 308).

Ora, nesta perspectiva, é possível observar que, de fato, a rápida evolução e progressão dos meios tecnológicos nos conduz a um panorama de efemeridade que parece marcar a existência de grande parte dos produtos contemporâneos.

De fato, a era digital aparenta ter como marca distintiva o modo como tudo aparece e desaparece em ciclos cada vez mais curtos, tornando a tecnologia e os conteúdos que esta alberga numa espécie de produtos do momento, marcas provisórias sujeitas à corrosão do tempo.

Assim, podemos, de fato, afirmar que, como sugerira Bauman (2001), ao conceitualizar sobre a sociedade líquida, todos os produtos parecem hoje efémeros, feitos para durar pouco e, num curto espaço de tempo, serem substituídos por novidades que, incessantemente, hão de surgir. Ora, assim sendo, e diante do exposto, no que diz respeito ao modo como a contemporaneidade impõe a noção de que, nesta era, tudo é, essencialmente, transitório, efémero e volátil, interessa-nos agora, particularmente, explorar a forma como a literatura digital, enquanto produto da era digital contemporânea, parece reproduzir, a partir das suas próprias produções literárias, esta tendência para assumir uma existência efémera, fugaz e transitória.

Nesta perspectiva, e partindo da noção de que, como defende Bauman (2001), a modernidade contribui para o derretimento das estruturas sólidas promovendo, em seu lugar, o surgimento de estruturas líquidas, pretendemos sugerir que a literatura digital, enquanto fruto da era contemporânea, parece refletir ela própria, pelas formas que hoje adquire, a passagem de um estado sólido - apoiado pela materialidade dos meios impressos - a um estado líquido ancorado na virtualidade, na dinâmica e na volatilidade do meio digital.

Assim, no nosso entender, esta liquidez da literatura digital parece encontrar-se relacionada com a sua própria materialidade, dinamismo e capacidade de transformação. Sublinhe-se, a este respeito, que revelando as obras literárias digitais, do ponto de vista orgânico e estrutural, uma incapacidade de manterem a solidez e a estabilidade associadas ao meio impresso, parecem então mostrar-se, através das propriedades favorecidas pela tecnologia digital, como 
obras líquidas em constante crescimento e transformação.

Repare-se, assim, que, à imagem e semelhança da sociedade moderna, cujas relações são fluídas, breves e voláteis, também o texto digital parece apresentar essa mesma "leveza", manifestando, na sua natureza, um carácter líquido e pouco duradouro.

Observe-se, a este respeito, que as obras literárias digitais podem apresentar, devido à sua modularidade ${ }^{3}$ e possibilidade de edição contínuas, mais do que uma versão ou atualização do mesmo texto, sendo possível afirmar que a forma como, a dado momento, uma obra se manifesta no ecrã é apenas uma forma provisória, efémera e volátil que, estando de passagem, em breve será substituída por uma nova forma que há de surgir.

Ora, neste sentido, vale a pena observar que, de fato, tratando-se a literatura digital interativa de uma literatura líquida, em constante processo de construção, reconstrução e evaporação, cada uma das atualizações sofridas pelo texto digital manifesta precisamente a essência efémera e volátil deste tipo de obras.

Acrescente-se, ainda, que, referindo-se Bauman ao modo como "as rotinas antigas e aparentemente eternas começam a se desintegrar" (BAUMAN, 2007, p. 100), estabelecendo um corte com o padrão e com a estabilidade, com a segurança e com a certeza, acreditamos que também a literatura digital interativa parece reproduzir uma tendência para, através de um novo suporte e de uma nova estrutura não-linear e fragmentária - a do hipertexto - promover uma quebra com o convencional e com o sólido, instaurando, em lugar da estabilidade, da segurança e da certeza, a desintegração, a indefinição, a insegurança e a imprevisibilidade que marcam a vida contemporânea e que são, simultaneamente, reproduzidas através do modo de funcionamento do ciberespaço.

Assim sendo, a este respeito, e por forma a verificar de que modo a desintegração, a indefinição e a imprevisibilidade, como marcas da contemporaneidade, parecem perpassar toda a produção literária em suporte digital, basta que observemos que ao abrir as páginas de um livro impresso nos deparamos já com a presença de um texto materializado e, por isso, estável, enquanto ao abrir as páginas de um livro digital somos precisamente confrontados com a existência de um texto em "estado potencial", virtual e imaterializado, que, ao invés de estabilidade, nos oferece a imprevisibilidade e a incerteza que advêm da maneira como o leitor interagirá com ele e do modo como, consequentemente, lhe imprimirá, através da sua interação, uma forma e um sentido.

Assim, e acompanhando a reflexão de Bauman acerca da contemporaneidade, diríamos que o

\footnotetext{
${ }^{3}$ Ao referir-nos à modularidade das obras literárias digitais referimo-nos à sua capacidade para, no seu todo, poderem ser "partidas" em elementos menores que as constituem (textos, pixéis, animações, sons, imagens, fragmentos de código binário, etc.) e editadas, em cada uma das suas partes constituintes, com relativa rapidez.
} 
livro digital, à imagem do homem contemporâneo, estabelece um corte com a padronização, rejeitando a estabilidade, a segurança e a certeza que advêm dos suportes fixos para promover, em seu lugar, uma nova estrutura - o hipertexto - que, pelas suas potencialidades, lhe permite libertar-se das "grilhetas" do universal, do total e do certo para se entregar, por via da multiplicidade, da não-linearidade e da aleatoriedade do texto digital, a um espaço de indefinição e possibilidade que, rompendo com a ordem, com a regularidade e com a previsibilidade, será pautado de acordo com a individualidade daquele que com ele interage.

Clarificando, diríamos, então, que, se a sociedade contemporânea entrega nas mãos do indivíduo moderno a responsabilidade de construir o seu próprio percurso, de alcançar a sua própria felicidade, a literatura digital parece, então, reproduzir esta tendência através da tentativa, cada vez mais intensa, de emancipação do leitor.

Repare-se, a este respeito, que, ao invés de oferecer ao leitor um texto sólido, total e completo, o autor digital trabalha hoje na construção do texto enquanto "espaço de possibilidades", um espaço onde o leitor pode, através da interação, definir o seu próprio percurso, imprimindo, a partir das suas escolhas, um determinado sentido à narrativa.

Note-se, assim, em analogia, que tal como no mundo contemporâneo, também no texto digital parece ser do indivíduo que recebe o texto a responsabilidade de desenhar, a partir das suas escolhas e das suas opções, um percurso que o conduza, neste contexto, não à felicidade, mas a uma das concretizações da narrativa.

Sublinhe-se, então, que também aqui, na literatura digital interativa, através da emancipação do leitor, parecemos ser remetidos para o ideal contemporâneo de que o indivíduo não deve encontrar-se sujeito a uma força maior (que, no caso da sociedade, é representada pela tradição e pelas instituições dominantes, e, no caso da literatura digital, é representada pelo autor) mas deve, pelo contrário, esforçar-se para construir, a partir da sua individualidade, o seu próprio caminho.

Por outra parte, e numa distinta linha de reflexão, foquemo-nos também no que diz respeito à questão da efemeridade associada às obras literárias digitais. Se, como temos oportunidade de observar através da teorização de Lichty (2003), Santaella (2013) e Heim (1993), o meio digital é marcado pela fugacidade e efemeridade, então, acreditamos ser pertinente observar que a literatura digital, produzida atualmente no e para o universo digital, parece ter uma tendência para ser adaptar, necessariamente, a esta característica do meio, tornando-se, ela própria, uma literatura do fluxo, do instantâneo, do móvel, do fugaz.

Ora, nesse sentido, e justificando a volatilidade e efemeridade do texto digital sublinhe-se, a título de exemplo, o modo como a narrativa de Pry, enquanto exemplo paradigmático, 
permite, devido à sua materialidade hipertextual, a possibilidade de reconstituir a obra a cada leitura. Repare-se, assim, a ilustrar esta característica, no fato de que ao ler o texto no "aqui e no agora", no "eterno presente" que lhe é apresentado, são oferecidos ao leitor trechos de textos e de vídeo que, pela estrutura não-linear e aleatória da obra (decorrente da sua específica materialidade digital) serão, necessariamente, diferentes dos trechos a que o mesmo leitor terá acesso se decidir ler o mesmo capítulo, uma segunda vez, segundos, minutos ou, até mesmo, horas depois.

Neste sentido, sublinhamos, portanto, destacando a fluidez, efemeridade e volatilidade das obras concebidas em suporte digital, que, de fato, parece ser possível observar, a partir do exemplo de Pry, que dada leitura ou dada concretização de uma obra literária digital é, na verdade, apenas uma aparição virtual, de carácter líquido e pouco duradouro.

Assim, consideramos, portanto, que o carácter líquido, transitório, efémero e volátil das formas concebidas e das relações vividas na contemporaneidade parece influenciar de modo determinante a forma de ser da literatura digital interativa que, ancorada num meio imaterializado, deslocalizado e móvel aparenta refletir, ela própria, uma necessidade de, enquanto literatura, e diante das transformações tecnológicas e, mais especificamente, da evolução dos suportes, recompor-se e adaptar-se em função das características do meio que a acolhe. Sublinhamos, então, neste sentido, que a passagem de uma literatura "sólida", associada ao meio impresso, a uma literatura "líquida", associada ao meio digital, parece ser, ela própria, resultado do processo de reconfiguração que atravessa toda a identidade da sociedade e do sujeito ao longo dos séculos XX e XXI e que acaba por influenciar de modo determinante a forma de ser e de viver dos indivíduos que hoje produzem literatura digital, afetando, consequentemente, as suas práticas criativas.

\section{Fragmentação do discurso e do indivíduo}

Prosseguindo com a tentativa de identificar algumas particularidades da contemporaneidade que nos permitam compreender as características essenciais da literatura digital interativa focar-nos-emos na ideia de que a sociedade contemporânea, em constante transformação e reformulação, promove um movimento de fragmentação do indivíduo.

Ora, para compreender este movimento de fragmentação é preciso, em primeira instância, observar que este é resultado de um conjunto de configurações históricas e sociais que deram origem à contemporaneidade, admitindo, neste sentido, que as mudanças estruturais e institucionais que puseram em xeque noções de unidade e universalidade previamente 
estabelecidas, nos conduzem, consequentemente, à chamada "crise de identidade" (HALL \& DU GAY, 1996; HALL, MCGREW, \& HELD, 1992). Vivida pelo sujeito da era contemporânea, esta crise de identidade relaciona-se com o fato de, como aponta Hall (1996), o sujeito já não ser definido biologicamente, como em épocas anteriores, mas de ser agora definido historicamente, em função das suas vivências, dos seus contextos, do seu contacto com o mundo.

Nesse sentido, o sujeito do século XXI caracteriza-se por viver num mundo onde novas identidades são formadas a cada momento, um mundo onde as identidades podem ser adotadas e descartadas com a mesma velocidade com que trocamos de roupa. $\mathrm{Na}$ verdade, como sugere o autor:

O sujeito pós-moderno (...) não tem uma identidade fixa, essencial e permanente. A identidade torna-se 'celebração móvel': formada e transformada continuamente em relação às formas pelas quais somos representados ou interpelados nos sistemas culturais que nos rodeiam (HALL, 1998, pp. 12-13).

Ora, neste sentido, vale a pena assinalar que a contemporaneidade parece, de fato, instalar - a partir das noções de quebra de unidade, de universalidade e de crença nas grandes narrativas e nas grandes instituições - uma crise de identidade a partir da qual é possível observar a transição de um sujeito centrado e estável (apoiado em quadros de referência que ofereciam estabilidade ao mundo social) para um sujeito fragmentado que, vivenciando o quadro de transformação social e de incerteza sobre os paradigmas antes estáveis e vigentes, procura hoje o seu próprio "eu”, a identificação com a sociedade em que vive.

A nova concepção do sujeito é, então, caracterizada pelo provisório, pela ideia de que a estrutura do indivíduo é desprovida de um único centro, apresentando vários focos de poder, e proporcionando sobre ele uma visão descentrada.

Deste modo, admitimos, portanto, que as velhas identidades, que durante tanto tempo estabilizaram o mundo social, parecem encontrar-se em declínio, fazendo surgir novas identidades e fragmentando, cada vez mais, o indivíduo moderno.

$\mathrm{Na}$ verdade, sublinhando a contemporaneidade essa falta de uma "identidade fixa", parece reafirmar, simultaneamente, a ideia de que o sujeito não pode viver como um ser pleno, íntegro e possuidor de uma essência que o identifica no mundo, mas deve aceitar, por seu turno, que a sua identidade se modifique por meio do contacto com o exterior.

Desta forma, o sujeito contemporâneo deve ser visto como um sujeito processual na medida em que também ele se fragmenta, partilhando distintos focos de atenção e passando a ser 
confrontado com uma multiplicidade de identidades possíveis, com as quais se vai, temporariamente, identificando.

Sublinhamos, portanto, que a modernidade possui um carácter desagregador e que, como sugere Hall:

O sujeito previamente vivido como tendo uma identidade unificada e estável está a tornar-se fragmentado; composto não de uma única, mas de várias identidades contraditórias ou não resolvidas. (HALL, 1998, p.12).

Neste sentido, e destacando a ideia de que a identidade vai sendo construída como um processo, afirmamos, portanto, que o sujeito contemporâneo assume identidades diferentes em distintos momentos.

Assim, e uma vez expostas as principais ideias no que diz respeito à questão da fragmentação do sujeito, cabe-nos perguntar-nos se poderá essa fragmentação estender-se ao discurso. Se retomarmos a obra A idade neobarroca (1987), de Omar Calabrese, aperceber-nos-emos que, ao tratar das características da contemporaneidade, o autor italiano sublinha a ideia de que o discurso contemporâneo é, acima de tudo, um discurso composto por fragmentos - um discurso que, à semelhança do sujeito moderno, não exprime inteireza.

Assim, para Calabrese o discurso da contemporaneidade, orientado pelo pensamento da época, traduziria o caos social da era contemporânea. Como sublinha o autor:

A estética do fragmento é um espalhar evitando o centro, ou a ordem, do discurso (...) 'a incoerência é preferível à ordem que deforma' (...) o fragmento como material criativo corresponde também a uma exigência formal e de conteúdo. Formal: exprimir o caos, a casualidade, o ritmo, o intervalo da escrita. De conteúdo: evitar a ordem das conexões, afastar para longe 'o monstro da totalidade' (CALABRESE, 1987, p. 10).

Neste sentido, e admitindo que, de fato, a desordem, a descontinuidade e a fragmentação são marcas do discurso contemporâneo interessa-nos, particularmente, mostrar de que modo a narrativa digital interativa, através da materialidade e da consequente fragmentariedade do objeto literário digital, reproduz, ela própria, uma estética de fragmentação.

Se observarmos que o texto literário digital é essencialmente atomístico - composto por um conjunto de fragmentos- textos, sons, imagens, vídeos - então, podemos notar que, de fato, a narrativa digital interativa parece reproduzir, a partir da sua própria estrutura, o ideal fragmentário proposto pela contemporaneidade. Neste mesmo sentido, observe-se ainda que, tal como o pensamento contemporâneo, e, nomeadamente, tal como a identidade do indivíduo 
da contemporaneidade, também o texto digital se apresenta como um todo descontínuo, disperso e avesso à ideia de totalidade. Note-se, a este respeito, que, ao invés de se apresentar com uma estrutura fixa, estável e unificadora, o texto digital apresenta-se, a partir das potencialidades do hipertexto, como um conjunto desordenado de peças, como uma estrutura não-linear e descentrada que propõe ao leitor a tarefa de lhe imprimir uma forma final através do processo de leitura.

Assim, o texto digital, constituindo-se como uma estrutura fractal, permite, no nosso entender, projetar, através da narrativa digital interativa, uma sensação de caos e de incompletude que entraria em diálogo com os princípios contemporâneos de destruição da universalidade, da totalidade e da certeza.

Assim sendo, sugerimos, portanto, a ideia de que a narrativa digital interativa, constituída por blocos autónomos de significação, parece ser, ela própria, metáfora da procura de identidade levada a cabo pelo sujeito moderno.

Atente-se, neste sentido, no fato de que, tal como o sujeito contemporâneo não tem, à partida, uma estrutura sólida que lhe garanta uma identidade fixa, sentindo, por isso, uma necessidade de, a partir da instabilidade do mundo, desenhar, gradualmente, a sua própria identidade, também a narrativa digital, desprovida da fixidez e da estabilidade que lhe oferecia o suporte impresso, parece procurar hoje, a partir das potencialidades do hipertexto (e nomeadamente da relação interativa com leitor), uma das suas muitas formas potenciais, ou seja, uma das suas identidades.

Nesta perspectiva, avançamos, portanto, com a ideia de que o sujeito contemporâneo, construindo a narrativa digital à sua imagem e semelhança cria, a partir das potencialidades do digital, um texto descentrado que, contendo em si um conjunto de textos potenciais, apenas será construído, em cada leitura, através da interação com aquele que o lê, numa das suas formas e numa das suas identidades. Neste sentido, também o texto digital parece manifestar um carácter processual uma vez que apenas pode ganhar forma através do processo de leitura e interação.

Assim, se o indivíduo da contemporaneidade é visto como um sujeito processual, um sujeito que constrói a sua identidade à medida que vai experienciando a vida, consideramos importante sublinhar a ideia de que parece ser este mesmo indivíduo que, à sua imagem e semelhança, vai construir, a partir das potencialidades do digital, uma narrativa que apenas pode ser construída à medida que é percorrida, lida e experimentada, através da interação, pelo leitor.

Complementando, diríamos ainda, que, se como referimos acima, o sujeito da 
contemporaneidade se afirma, essencialmente, como um sujeito descentrado, então, será este mesmo sujeito que, uma vez mais, construindo o texto à sua imagem e semelhança, nos vai apresentar, a partir do digital, uma estrutura textual com múltiplas entradas, múltiplas saídas e múltiplos focos de atenção.

Reforçando o paralelismo: se o sujeito da contemporaneidade possui uma identidade marcada pelo provisório, avançamos com a hipótese de que também as suas produções, nomeadamente as produções literárias digitais, possam refletir, através da sua forma, uma provisoriedade e uma efemeridade que decorrem do próprio modo de vida contemporâneo quando aliado às propriedades e potencialidades técnicas dos novos dispositivos que, entre outras coisas, possibilitam a constante alteração/atualização do texto digital.

Ora, nesta perspectiva, e diante do disposto, pretendemos aqui sugerir que o texto digital reflete, a partir da sua própria estrutura e materialidade, a fragmentação vivida pelo sujeito contemporâneo. Assim, consideramos, portanto, que a literatura digital, vista como uma literatura que carece de centro e de identidade fixa, parece assumir-se, ela própria, à imagem do sujeito que a produz, como uma literatura fragmentada, dispersa e atomística que apenas pode ganhar sentido através do processo de leitura.

Assim, e por forma a completar a reflexão, interessa-nos, de modo particular, mostrar que, de fato, a literatura digital, através da narrativa interativa, parece ela própria acompanhar a evolução do sujeito contemporâneo.

Note-se, a este respeito, e no nosso entender, que se a literatura impressa, pela sua própria estrutura - rígida, estável e sólida - nos oferece um olhar sobre um sujeito unificado, de identidade firme e de relações duradouras, a literatura digital, por seu turno - dinâmica, líquida e processual - oferece-nos, pelo contrário, a possibilidade de, a partir da sua essência, antever um sujeito fragmentado, líquido e múltiplo, sobretudo do ponto de vista identitário.

Note-se, assim, que se a literatura impressa é, caracterizada, na maior parte dos casos, pela unidade das linguagens que a constituem, na literatura digital essa unidade parece, a partir da materialidade do digital, e mais especificamente, a partir da estrutura do hipertexto, fragmentar-se. Observe-se, a este respeito, que enquanto na literatura impressa todo o texto se apresenta como uma espécie de "bloco" sólido e uniforme, na literatura digital todo o texto deixa antever, a partir da sua própria estrutura, a fragmentariedade de que é constituído. Repare-se, neste sentido, que todo o texto digital pode, hipoteticamente, ser dividido em unidades mínimas, as chamadas lexias, permitindo-nos, a partir dessa fragmentação, observar a existência de diversas linguagens autónomas, de diversos códigos e de diversos blocos de sentido que, juntos, formam a unidade da narrativa. 
Assim, e focando-nos, por agora, apenas na questão estrutural, consideramos ser possível admitir que o texto digital se apresenta, na sua essência, e devido à estrutura fragmentária e ramificada que se encontra na sua base - o hipertexto -, como uma réplica da fragmentação do discurso contemporâneo.

Desta forma, e diante do exposto, sugerimos, portanto, que se admita a hipótese da "velha" identidade da literatura, que durante tanto tempo foi associada à estabilidade e durabilidade do suporte impresso, estar hoje a ser gradualmente repensada a partir da literatura digital e, concretamente, a partir da narrativa digital interativa.

$\mathrm{Na}$ verdade, estabelecendo um paralelo com a evolução do sujeito contemporâneo, sugerimos que a literatura digital, à semelhança do homem moderno, nos permite antever o declínio de uma velha identidade, associada a ideais de unidade, solidez e estabilidade, dando lugar a uma nova identidade que, reconfigurada pelos novos suportes, parece ser marcada pela fragmentação, pela provisoriedade e pela liquidez.

Em suma, admitimos a hipótese de que a literatura digital e a narrativa interativa, sendo criadas por um indivíduo contemporâneo líquido e fragmentado, estejam, elas próprias, a partir dos novos suportes, a manifestar uma tendência para dissolver a solidez e a estabilidade. Note-se, a justificar a nossa posição, que, de fato, se observarmos, parece ser hoje impossível pensar um texto digital, construído a partir de uma estrutura alinear e ramificada, que possa ser visto como um texto sólido e de identidade fixa.

Sublinhe-se, assim, que o texto digital, pela sua materialidade, deve ser pensado à luz do sujeito que o produz, como um texto de carácter líquido e mutável, marcado pela possibilidade de assumir, em diversos momentos, diferentes identidades.

Senão vejamos: poderemos afirmar que um texto digital, nas suas diversas possibilidades de realização (nos seus diversos percursos de leitura), é ainda o mesmo texto, mantém ainda a mesma identidade? Ou devemos considerar, pelo contrário, que, enquanto estrutura potencial, o texto digital assume, em cada uma das suas realizações, em cada uma das suas concretizações, uma das muitas identidades que traz inscritas na sua génese?

Ora, diante destas questões, gostaríamos então de sublinhar, em diálogo com a estética da contemporaneidade, que se o individuo é marcado pela multiplicidade de identidades, também o texto digital, neste sentido, aparenta sê-lo. Na verdade, sendo programado como um texto que contém em si, potencialmente, muitos caminhos e muitas possibilidades de realização, também este, de acordo com as escolhas e interações do leitor, parece poder ganhar, a partir do processo de leitura, múltiplas identidades, múltiplos desfechos e múltiplas formas de ser. Ora, diante dos argumentos expostos, sugerimos, então, a hipótese de ser possível estabelecer 
uma aproximação entre o ideal contemporâneo de fragmentação do discurso e do indivíduo e a própria natureza formal da literatura digital e da narrativa interativa.

\section{Conclusão}

Desta forma, e em jeito de conclusão, sublinhamos, portanto, ser possível observar a narrativa digital interativa através da lente da contemporaneidade e dela extrair um conjunto de características que formando parte da vivência, do modo de pensamento e de atuação do sujeito contemporâneo são, simultaneamente, parte integrante das práticas literárias em meios digitais.

Atente-se, assim, neste sentido, que, como temos vindo a defender, concepções como as de fragmentaridade, multiplicidade, procura de identidade, provisoriedade, descentramento, liquidez e processualidade, vistas enquanto elementos definidores do indivíduo contemporâneo, se assumem aqui, elas próprias, como importante instrumento para compreender a atual forma de ser da literatura digital interativa, abrindo-nos, consequentemente, as portas a entender novas concepções, novas formas e novas realidades que advém da introdução dos meios e dos suportes digitais no processo de criação literária. 


\section{REFERÊNCIAS}

ANDERSON, P. As origens da pós-modernidade. Rio de Janeiro: Zahar, 1999.

BAUMAN, Z. Globalização: as consequências humanas. Rio de Janeiro: Zahar, 1999.

BAUMAN, Z. Modernidade Líquida. Rio de Janeiro: Zahar, 2001.

BAUMAN, Z. Tempos Líquidos. Rio de Janeiro: Zahar, 2007.

BAUMAN, Z. A Arte da Vida. Rio de Janeiro: Zahar, 2009.

BAUMA, Z. Vigilância Líquida. Rio de Janeiro: Zahar, 2013.

CALABRESE, O. A idade neobarroca. Lisboa: Edições 70, 1987.

CASTELlS, M. A Sociedade em Rede. São Paulo: Paz e Terra, 1999.

DOWBOR, L. Economia da Cultura Digital. In R. Savazoni, \& S. Cohn, Cultura Digital.br. p.56-65. Rio de Janeiro: Azougue Editorial, 2009.

FREZZA, M.; GRISCI, C. I.; KESSLER, C. K. Tempo e Espaço na Contemporaneidade: uma análise à partir de uma Revista Popular de Negócios. RAC, pp. 487-503. jul., 2009.

Disponível em: <http://www.scielo.br/pdf/rac/v13n3/v13n3a09.pdf>. Acesso em: 20 ago. 2016.

GORMAN, S.; CANNIZZARO, D. Pry. Tender Claws LLC, 2014.

HALL, S. A identidade cultural na pós-modernidade. Rio de Janeiro: DP\&A, 1998.

HALL, S.; DU GAY, P. Questions of Cultural Identity. Nova Iorque: SAGE Publications Ltd, 1996.

HARGREAVES, A. O Ensino na Sociedade do Conhecimento: a educação na era da insegurança. Porto: Porto Editora, 2003.

HARVEY, D. A condição pós-moderna. São Paulo: Edições Loyola, 2004.

HEIM, M. The metaphysics of virtual reality. Oxford: Oxford University Press, 1993.

JAMESON, F. Postmodernism or the Cultural Logic of Late Capitalism. Duke: Duke University Press, 1991.

KARR, N. A Internet mudou a nossa percepção do tempo. 28 nov. 2012. Disponível em: <pt: https://www.publico.pt/tecnologia/noticia/a-internet-mudou-a-nossa-percepcao-dotempo-1573458>. Acesso em: 7 ago. 2016.

LICHTY, P. Histórias do desaparecimento/desaprecimento de histórias. In: D. Domingues. Arte e Vida no Século XXI: tecnologia, ciências e criatividade. p. 206-315. São Paulo: Editora UNESP, 2003. 
MAFFESOLI, M. No fundo das aparências. Rio de Janeiro: Editora Vozes, 1999.

NEGROPONTE, N. Being Digital. Alfred A. Knopf, 1995.

NEGROPONTE, N. El mundo digital: Un futuro que ya ha llegado. Espanha: Ediciones B., 2000 .

SANTAELLA, L. Comunicação Ubíqua: Repercussões na cultura e na educação. São Paulo: Paulus, 2013.

TESSMAN, R. Explorando a era digital: ciberespaço. 11 out. 2013. Disponível em:

$<$ http://ramontessmann.com.br/explorando-era-digital-ciberespaco>. Acesso em: 12 abr. 2016, em Ramon Tessman.

VIRILIO, P. A bomba informática. São Paulo: Estação Liberdade, 1999. 